Happening Gradually

Author(s): Christopher Piñón

Proceedings of the Twenty-Sixth Annual Meeting of the Berkeley

Linguistics Society: General Session and Parasession on Aspect (2000), pp. $445-456$

Please see "How to cite" in the online sidebar for full citation information.

Please contact BLS regarding any further use of this work. BLS retains copyright for both print and screen forms of the publication. BLS may be contacted via http://linguistics.berkeley.edu/bls/.

The Annual Proceedings of the Berkeley Linguistics Society is published online via eLanguage, the Linguistic Society of America's digital publishing platform. 


\title{
Happening gradually
}

\author{
CHRISTOPHER PIÑÓN* \\ Universität Düsseldorf
}

In this paper I propose a semantics for gradually, a manner adverb. Gradually contrasts with suddenly, as aptly illustrated by the following example:

At some point the economy will slow; the only question is whether this will happen gradually or suddenly. (WP, 21 Oct. 1999, p. A28)

I have three main reasons for studying gradually. First, as far as I am aware, there is no analysis of gradually in the literature. Second, although gradually is not generally considered to be sensitive to aspectual distinctions, it actually diagnoses a subclass of activities and accomplishments. Third and finally, the semantics of gradually brings together change and comparison.

\section{Syntactic considerations}

Gradually, like many adverbs, is not tied to a single position in a clause:

(2) a. Gradually(,) the ice melted. (initial)

b. The ice gradually melted. (preverbal)

c. The ice melted gradually. (postverbal)

Following Jackendoff (1972, chap. 3), I distinguish three basic surface positions in a clause for -ly adverbs: initial position, preverbal position (i.e., immediately before the main verb or an auxiliary verb), and postverbal position (i.e., after the main verb without an intervening pause).

\footnotetext{
* I am grateful to those who attended my talk for their comments and to Sebastian Löbner for useful discussion. Any errors are my own. With one exception, the naturally occurring examples are all taken from the Washington Post $(W P)$. This work was supported by the German Science Foundation (SFB 282, Teilprojekt D3) and a fellowship from Collegium Budapest during the academic year 1997/98. This study has its origins in unpublished work of mine on German allmählich 'gradually'.
} 
Table 1: Distribution of gradually

\begin{tabular}{|r|r|r|}
\hline Occurrences & 79 & $100 \%$ \\
\hline \hline Initial & 5 & $6 \%$ \\
\hline Preverbal & 60 & $76 \%$ \\
\hline Postverbal & 14 & $18 \%$ \\
\hline
\end{tabular}

The paradigm exemplified in (2) raises three questions: (i) Is there a default position for gradually? (ii) Does the meaning of gradually vary according to position? (iii) What kind of syntactic unit does gradually combine with?

My answer to question (i) is based on a corpus of 79 naturally occurring sentences with gradually that I culled from the Washington Post. In this corpus gradually occupies preverbal position $76 \%$ of the time, postverbal position $18 \%$ of the time, and initial position a mere $6 \%$ of the time, as summarized in Table 1 . Such a distribution strongly suggests that the preverbal position is the default position for gradually, a conclusion that also accords with one's intuitions about the data.

In answer to question (ii) I adopt the strongest hypothesis that the lexical semantics of gradually is constant across positions. Even so, other factors can and do vary according to position, such as the scope of gradually and whether it is focused or not.

A case of scopal variation is the following:

(3) a. Gradually(,) every block of ice melted.

b. Every block of ice gradually melted.

c. Every block of ice melted gradually.

Whereas (3a) asserts that the melting of the set of blocks of ice was gradual, (3c) states that the melting of every individual block of ice was gradual. ( $3 b)$ seems to allow for either interpretation. ${ }^{1}$

Evidence for a scopal ambiguity in (3) comes from the effect of inserting suddenly into postverbal position:

(4) a. Gradually(,) every block of ice melted suddenly.

b. ?Every block of ice gradually melted suddenly.

c. \#Every block of ice melted gradually and suddenly.

It is possible to interpret (4a) as asserting that the melting of the set of blocks of ice was gradual but that the melting of each individual block of ice was sudden, which is imaginable if there were many small blocks of ice that melted one after another.

1 Jackendoff treats the preverbal position as structurally ambiguous, as dominated by the $\mathrm{S}$ node or the VP node. In his analysis, the initial position is dominated by the $S$ node and the postverbal position by the VP node. 


\section{Happening gradually}

(4c), in contrast, is contradictory, because the melting of each individual block of ice could not be both gradual and sudden. (4b) can receive either a consistent or a contradictory interpretation (though the consistent interpretation is much more naturally expressed by (4a)).

A natural way of focusing gradually is to place it in postverbal position. Indeed, in postverbal position it is hard not to pronounce gradually with a focus accent. This is evident in (1), where gradually is contrasted with suddenly. But it is clear in other examples as well:

(5) a. A baseball fan should be able to progress gradually toward rapture, or heartbreak. (WP, 22 Oct. 1999, p. D11)

b. Kipke testified he became aware of the side effects only gradually. (WP, 13 Jan. 2000, p. D02)

The writer of (5a) complains that baseball games have become less enjoyable, with stadiums emptying early, and describes how a baseball fan should be able to progress toward rapture. The question to which $(5 b)$ is an answer is how soon Kipke knew about the harmful side effects of the drugs that he dispensed.

Sometimes it is more difficult to say why gradually appears in initial position (as opposed to preverbal position):

(6) a. Gradually, the Nigerians pushed the rebels out of Freetown. (WP, 9 Jan. 2000, p. W08)

b. Gradually the practice [of using curse words] seeped onto TV through cable channels and then so-called pioneering dramas like NYPD Blue, [...] (WP, 10 Jan. 2000, p. C04)

Although it would be easy to claim that gradually is 'topicalized' in such examples, it is far from obvious what this should amount to semantically or pragmatically. I suspect that the main motivation for placing gradually in initial position in these examples is to give it scope over tense. For example, (6a) seems to mean that it gradually came about that the Nigerians pushed the rebels out of Freetown. If correct, then a consequence of having gradually scope over tense is that gradually asserts gradualness not of the situation directly described by the clause but rather of what leads up to that situation.

A much clearer example of gradually scoping over tense is provided in (7), given that gradually is otherwise incompatible with stative descriptions, as we will see in the next section.

(7) Gradually there's no more work for her. (I married a communist, Philip Roth, p. 309, Vintage Books, 1998.) 
This example may be paraphrased as 'Gradually it comes about that there's no more work for her'.

In sum, although the placement of gradually is associated with semantic and pragmatic effects, I see no reason to reject the hypothesis that its lexical semantics remains constant no matter which position it appears in.

Turning at last to question (iii), since the preverbal position is the default position of gradually, I take this as indicating that gradually combines with a (subjectinternal) VP:

$$
\text { [VP gradually [vP ]] }
$$

More precisely, the syntactic unit that gradually subcategorizes for is a VP in which the (untensed) verb has combined with its arguments.

\section{Interaction with aspect}

In this section I examine the interplay of gradually with Vendler's (1967) four aspectual classes. I presuppose familiarity with the use of for-and in-adverbials as tests for distinguishing states and activities from accomplishments and achievements. Although gradually is not usually taken to be an aspectual adverb, it is sensitive to a type of change characteristic of a subclass of activities and accomplishments.

A salient intuition about the meaning of gradually is that it requires some sort of change, for whatever happens gradually should in fact happen and not just hold. Since ordinary states are usually not thought to involve change, there is reason to expect that they will be incompatible with gradually, as is indeed the case:

(9) a. \#Peter gradually loved Mary (in high school).

b. \#Mary gradually knew the answer (to the question).

It may be possible to interpret (9a) and (9b) as asserting that Peter gradually came to love Mary and that Mary gradually came to know the answer, respectively, but this would require reinterpreting the VP argument of gradually in each case so that it is no longer stative. ${ }^{2}$

States differ as to whether there is a scale of intensity along which they are realized. For example, although you can love someone a little or a lot, you cannot know the answer to a question a little or a lot. Applied to a state, the adverbial more and more asserts that the degree of intensity of the state steadily increases over time (compare (10) with the unacceptable \#Mary knew the answer more and more):

\footnotetext{
${ }^{2}$ This reinterpretation might be accounted for by having graduallytake scope over tense, as suggested in the previous section. Notice that Gradually, Peter loved Mary and Gradually, Mary knew the answer sound much better than (9a) and (9b) on the reinterpretation. Recall (7) as well.
} 


\section{Happening gradually}

(10) Peter loved Mary more and more (as he grew older).

Once a state is so modified, gradually is compatible with the result: ${ }^{3}$

(11) Peter gradually loved Mary more and more (as he grew older).

Above I spoke of 'ordinary states' and by this I meant states as denoted by stative verbs. However, the progressive aspect is also often considered to be statedenoting, and it turns out gradually is compatible with a variety of progressives:

(12) a. Moreover, the government feared that Hamas was gradually radicalizing Jordan's own broadly popular, and largely peaceable, Islamic movement. (WP, 7 Oct. 1999, p. A25)

b. We never filed for bankruptcy protection and are gradually paying off all our creditors. (WP, 9 Oct. 1999, p. G19)

This difference in behavior between ordinary states and 'progressive states' suggests that gradually has narrow scope with respect to the progressive operator in progressives, i.e., graduallyfirst combines with a nonprogressive VP and then the progressive operator applies to the result. If this is the correct order of combination, then we predict that if gradually is incompatible with a given nonprogressive VP, then it no acceptable progressive will be derivable. Such an example is offered in (13), where the unacceptability of (13b) with gradually has the consequence that its progressive form in (13b) is also unacceptable, despite the acceptability of the progressive without gradually in (13a).

(13) a. Mary was standing on the corner.

b. \#Mary gradually stood on the corner.

c. \#Mary was gradually standing on the corner.

Since activities uncontroversially do involve change, they can be used to show that not any kind of change suffices for gradually, because many activities, like ordinary states, are incompatible with gradually:

(14) a. \#Mary gradually ran (in the park).

b. \#Peter gradually wrote letters (to his mother).

c. \#I gradually drank wine (at the party).

The problem in (14) is not that there is no change, but rather that no scale of change is made explicit. If more and more is employed once again to make the intended scale explicit, either as an adverbial (see (15a)) or as a determiner (see

\footnotetext{
${ }^{3}$ The result of modifying a state by more and more is an activity.
} 
(15b) and (15c)), then the results are compatible with gradually: ${ }^{4}$

(15) a. Mary gradually ran more and more quickly (towards the finish).

b. Peter gradually wrote more and more letters (to his mother).

c. I gradually drank more and more wine (at the party).

In (15a) quickly specifies the scale (quickness of motion) and more and more expresses that the quickness of Mary's running steadily increased over time. In (15b) more and more states that the number of letters that Peter wrote steadily increased over time. $(15 c)$ is analogous.

Even so, not all activity verbs require modification by more and more in order to be compatible with gradually:

(16) a. The economy gradually expanded (for three years).

b. The sky gradually darkened (for two hours).

The question is what distinguishes the acceptability of gradually in (16) from its unacceptability in (14). I suggest that verbs like expand and darken, in contrast to those like run, write, and drink, have a scale of change built into their meaning. Although all of these verbs are activities, only expand and darken assert explicit change along a scale (namely, increase in extent and darkness, respectively). Other examples of verbs that pattern like expand are rise, widen, and lengthen, not to mention combinations of become with the comparative form of an adjective (e.g. become smaller).

Gradually occurs unproblematically with an array of accomplishments, as seen in (17). Such accomplishments all involve change along a scale, which intuitively accounts for their compatibility with gradually. In (17a) the scale is the extent of power, in (17b) it is the amount of sugar, and in (17c) it is the extent of destruction of the motor neurons.

(17) a. Only in the last few centuries, as their power gradually diminished to almost nothing, have British monarchs been able to sit securely on their thrones. (WP, 13 Oct. 1999, p. H01)

b. Gradually add the remaining $1 / 4$ cup sugar and continue beating until the whites are glossy and firm. (WP, 27 Oct. 1999, p. M34)

c. Over the months, though, the disease, which gradually destroys the motor neurons that carry the brain's messages throughout the body, has increasingly debilitated her. (WP, 8 Jan. 2000, p. B03)

Nevertheless, not all accomplishments are equal in this respect. For example, the following sentences are questionable if taken to mean that the rescuing and

\footnotetext{
${ }^{4}$ The result of modifying an activity by more and more is again an activity.
} 


\section{Happening gradually}

buying were gradual:

(18) a. ?The lifeguard gradually rescued Peter (at the beach).

b. ?Mary gradually bought the house (in that street).

This becomes clearer if gradually appears in postverbal position:

(19) a. \#The lifeguard rescued Peter gradually (at the beach).

b. \#Mary bought the house gradually (in that street).

The examples in (18) can be understood as asserting that what led up to the lifeguard's rescuing of Peter and Mary's buying of the house was gradual, but this again requires reinterpreting the VP so that what gradually appears to modify semantically (the type of events denoted by the VP) is not what it actually modifies (the type of events leading up to the events denoted by the VP). ${ }^{5}$

The problem with (18) is not that there is any inherent incompatibility between gradually and rescue or buy. Indeed, if we replace the object NPs in (18) with plural definite NPs, the results are compatible with gradually:

(20) a. The lifeguard gradually rescued the children (at the beach).

b. Mary gradually bought the houses (in that street).

The difference between (18a) and (20a) is that if the lifeguard rescues Peter, she rescues him as whole and not part by part, but if she rescues the children, she may well rescue them one after the other, which is what gradually requires. The same difference holds between (18b) and (20b).

Although gradually appears at first glance to be compatible with achievements, it actually forces an achievement to be reinterpreted as an accomplishment, similar to what we saw with states and accomplishments (recall (9) and (18), respectively), though the reinterpretation of achievements is much more natural and nearly automatic:

(21) a. The speaker only gradually realizes what the weather is telling her: "as I looked (for things did not look) up." (WP, 10 Oct. 1999, p. X12)

b. Mary gradually noticed the new student in her class.

c. Peter gradually reached the summit.

The relevant parts of (21a) and (21b) can be paraphrased as 'gradually comes to realize' and 'gradually came to notice', respectively, and (21c) has the approximate paraphrase 'gradually succeeded in reaching'.

In sum, gradually diagnoses a subclass of activities and accomplishments. This

${ }^{5}$ Recall the discussion of (9), where states allowed for a similar reinterpretation. See also footnote 2 . 
statement requires a caveat: in general it is possible for gradually to modify what leads up to the situation described by the VP. This reinterpretation works most naturally with achievements, but it is also possible with states, activities, and accomplishments and is most inviting when gradually appears in initial position, where graduallyarguably scopes over tense.

\section{Analysis: events and degrees}

For the analysis of gradually below I presuppose a domain of interpretation that includes the following basic sorts and relations:

- a sort of (physical) objects: $\mathrm{x}, \mathrm{y}, \mathrm{z}, \ldots$

- a sort of events (in the broad sense, including states): e, $\mathrm{e}^{\prime}, \mathrm{e}^{\prime \prime}, \ldots$

- a sort of degrees: $\mathrm{d}, \mathrm{d}^{\prime}, \mathrm{d}^{\prime \prime}, \ldots$

- a proper part relation on objects and events: $\sqsubset$

- a temporal precedence relation on events: $\prec$

- a less-than relation on degrees: <

The definitions of the (improper) part relation (on objects and events) and the less-than-or-equal relation (on degrees) are stated with the help of identity in the usual way, as in (22), where $v, v^{\prime}, v^{\prime \prime}, \ldots$ are variables for objects or events.
a. $\quad v \sqsubseteq v^{\prime} \stackrel{\text { def }}{=} v \sqsubset v^{\prime} \vee v=v^{\prime} \quad\left(v\right.$ is a part of $\left.v^{\prime}\right)$
b. $\quad d \leq d^{\prime} \stackrel{\text { def }}{=} d<d^{\prime} \vee d=d^{\prime} \quad\left(d\right.$ is less or equal to $\left.d^{\prime}\right)$

I also define both an initial proper part and an initial part relation on events:

$$
\text { a. } \begin{aligned}
& \mathrm{e} \sqsubset \text { ini } \mathrm{e}^{\prime} \stackrel{\text { def }}{=} \mathrm{e} \sqsubset \mathrm{e}^{\prime} \wedge \neg \exists \mathrm{e}^{\prime \prime}\left[\mathrm{e}^{\prime \prime} \sqsubseteq \mathrm{e}^{\prime} \wedge \mathrm{e}^{\prime \prime} \prec \mathrm{e}\right] \wedge \forall \mathrm{e}_{1} \forall \mathrm{e}_{2}\left[\mathrm{e}_{1} \sqsubseteq \mathrm{e} \wedge \mathrm{e}_{2} \sqsubseteq \mathrm{e} \rightarrow\right. \\
&\left.\neg \exists \mathrm{e}^{\prime \prime}\left[\mathrm{e}^{\prime \prime} \sqsubseteq \mathrm{e}^{\prime} \wedge \mathrm{e}_{1} \prec \mathrm{e}^{\prime \prime} \wedge \mathrm{e}^{\prime \prime} \prec \mathrm{e}_{2} \wedge \neg \mathrm{e}^{\prime \prime} \sqsubseteq \mathrm{e}\right]\right]
\end{aligned}
$$

(e is an initial proper part of $\mathrm{e}^{\prime}$ )
b. $\quad e \sqsubseteq_{\text {ini }} \mathrm{e}^{\prime} \stackrel{\text { def }}{=} \mathrm{e} \sqsubset_{\mathrm{ini}} \mathrm{e}^{\prime} \vee \mathrm{e}=\mathrm{e}^{\prime} \quad\left(\mathrm{e}\right.$ is an initial part of $\left.\mathrm{e}^{\prime}\right)$

The condition beginning with the universal quantification on the first line of (23a) is needed because no assumption is made regarding the connectedness of events. Informally, this definition ensures that if $\mathrm{e}^{\prime}$ is an initial proper part of $e$, then $\mathrm{e}^{\prime}$ cannot temporally 'skip over' any parts $e^{\prime \prime}$ of $e$.

Although I postulate a domain of degrees, I have not said anything about what degrees are. For the purpose of analyzing gradually it suffices to think of degrees as (positive) intervals on a scale, where a scale is an ordered set of points along some dimension (see Hay, Kennedy, and Levin 1999 for discussion). For example, if the dimension is extent of destruction, then degrees ( $q u a$ positive intervals) on the associated scale can model the extent to which an object is destroyed. 


\section{Happening gradually}

My analysis of gradually is given in (24), where gradually is treated as a modifier of relations $R$ between events e and degrees $d$ and asserts that as e unfolds, the degree of $e$ as determined by $R$ steadily increases. ${ }^{6}$ Technically, this is implemented by mapping the set of initial parts of e into a set of degrees determined by $R$ so that the ordering on initial parts is preserved in the ordering on degrees. To ensure that the mapping is nonvacuous, it is required that e have an initial proper part. ${ }^{7}$

$$
\begin{aligned}
& \text { gradually } \leadsto \lambda R \lambda d \lambda e\left[R ( e , d ) \wedge \forall e ^ { \prime } \forall e ^ { \prime \prime } \left[e^{\prime} \sqsubset_{\text {ini }} e^{\prime \prime} \wedge e^{\prime \prime} \sqsubseteq\right.\right. \text { ini } \\
& \left.\left.\quad \exists d^{\prime} \exists d^{\prime \prime}\left[R\left(e^{\prime}, d^{\prime}\right) \wedge R\left(e^{\prime \prime}, d^{\prime \prime}\right) \wedge d^{\prime}<d^{\prime \prime} \wedge d^{\prime \prime} \leq d\right]\right] \wedge \exists e^{\prime}\left[e^{\prime} \sqsubset_{\text {ini }} \text { e }\right]\right] \\
& \quad \stackrel{\text { def }}{=} \text { Gradual }
\end{aligned}
$$

I adopt a standard assumption of event-based semantic approaches that verbs have an event argument (e.g., see Krifka 1992). Since gradually needs a relation between events and degrees to apply to, the main task is to account for how a degree argument comes into play in the course of semantic composition. In general, there are three ways in which this can happen.

The first way is for verbs to have a degree argument to begin with. Such verbs are presumably the exception rather than the rule, but 'degree achievements' are good candidates, as argued for on independent grounds by Hay et al. (1999). Additional support for this idea comes from the observation that degree achievements combine very well with gradually. Consider, for example, the analysis of (16a) with the degree achievement expand:

$$
\begin{aligned}
& \text { a. expand } \sim \lambda \times \lambda \mathrm{d} \lambda \mathrm{e}[\text { Expand }(\mathrm{e}, \mathrm{d}, \mathrm{x})] \\
& \text { b. the economy expand } \sim \lambda \mathrm{d} \lambda \mathrm{e}[\text { Expand }(\mathrm{e}, \mathrm{d}, \text { The-economy })] \\
& \text { c. the economy gradually expand } \sim \\
& \quad \lambda \mathrm{d} \lambda \mathrm{e}\left[\text { Gradual }\left(\mathrm{e}, \mathrm{d}, \lambda \mathrm{d}^{\prime} \lambda \mathrm{e}^{\prime}\left[\text { Expand }\left(\mathrm{e}^{\prime}, \mathrm{d}^{\prime}, \text { The-economy }\right)\right]\right)\right]
\end{aligned}
$$

As shown in (25a), expand is treated as a three-place relation between events, degrees, and objects, and can be paraphrased as 'object $x$ expands in event $e$ to degree d'. The formula in (25c) asserts that the degree to which the economy expands steadily increases as the event unfolds. Other verbs that pattern like expand (see the discussion of (16)) would also be analysed as having a degree argument.

The second way is for a degree argument to be introduced by a modifier, most notably more and more. This is the way for stative and most activity verbs to become compatible with gradually (see (9), (11), (14), and (15)). Consider, for instance, the analysis of (15a) with run:

\footnotetext{
${ }^{6}$ Merriam Webster's Collegiate Dictionary characterizes the meaning of gradually (and gradual) as 'proceeding by steps or degrees' and 'moving, changing, or developing by fine or often impercepti-
ble degrees'. ${ }^{7}$ Perhaps the of relying on default existential quantificationtentially quantifies over the degrees $d$ in (24) (instead
} 
(26)
a. $\quad \operatorname{run} \leadsto \lambda \times \lambda \mathrm{e}[\operatorname{Run}(e, x)]$
b. Mary run $\sim \lambda e[\operatorname{Run}(e$, Mary $)]$
c. more and more quickly $\leadsto \lambda \mathrm{P} \lambda \mathrm{d} \lambda \mathrm{e}[\mathrm{P}(\mathrm{e}) \wedge$ Quick $(\mathrm{e}, \mathrm{d}) \wedge$

$$
\begin{aligned}
& \forall \mathrm{e}^{\prime} \forall \mathrm{e}^{\prime \prime}\left[\mathrm { e } ^ { \prime } \sqsubset _ { \text { ini } } \mathrm { e } ^ { \prime \prime } \wedge \mathrm { e } ^ { \prime \prime } \sqsubseteq _ { \text { ini } } \mathrm { e } \rightarrow \exists \mathrm { d } ^ { \prime } \exists \mathrm { d } ^ { \prime \prime } \left[\mathrm{P}\left(\mathrm{e}^{\prime}\right) \wedge \text { Quick }\left(\mathrm{e}^{\prime}, \mathrm{d}^{\prime}\right) \wedge\right.\right. \\
& \left.\left.\left.\quad \mathrm{P}\left(\mathrm{e}^{\prime \prime}\right) \wedge \text { Quick }\left(\mathrm{e}^{\prime \prime}, \mathrm{d}^{\prime \prime}\right) \wedge \mathrm{d}^{\prime}<\mathrm{d}^{\prime \prime} \wedge \mathrm{d}^{\prime \prime} \leq \mathrm{d}\right]\right] \wedge \exists \mathrm{e}^{\prime}\left[\mathrm{e}^{\prime} \sqsubset_{\text {ini }} \mathrm{e}\right]\right] \\
& \stackrel{\text { def }}{=} \text { More-more-quick }
\end{aligned}
$$

d. Mary run more and more quickly $\sim$

$\lambda \mathrm{d} \lambda \mathrm{e}\left[\right.$ More-more-quick(e, $\mathrm{d}, \lambda \mathrm{e}^{\prime}\left[\operatorname{Run}\left(\mathrm{e}^{\prime}\right.\right.$, Mary $\left.\left.\left.)\right]\right)\right]$

e. Mary gradually run more and more quickly $\sim$

$$
\begin{aligned}
& \lambda \mathrm{d} \lambda \mathrm{e}[\text { Gradual(e, } \mathrm{d} \text {, } \\
& \left.\left.\quad \lambda \mathrm{d}^{\prime} \lambda \mathrm{e}^{\prime}\left[\text { More-more-quick }\left(\mathrm{e}^{\prime}, \mathrm{d}^{\prime}, \lambda \mathrm{e}^{\prime \prime}\left[\operatorname{Run}\left(\mathrm{e}^{\prime \prime}, \text { Mary }\right)\right]\right)\right]\right)\right]
\end{aligned}
$$

Since the analysis of [VP Mary run] in (26b) does not involve a degree argument, it is incompatible with gradually, as seen in (14a). However, the situation is remedied by the adverbial more and more quickly, which adds the necessary degree argument. The semantics of more and more quickly in (26c) makes use of a relation Quick between events and degrees (intuitively, 'event e is quick to degree d'). Notice that the meaning of more and more quickly is very similar to that of gradually, though with two notable differences. ${ }^{8}$ The first is that more and more quickly specifies the scale of change (quickness of motion), whereas gradually leaves this to the relation $\mathrm{R}$ that it applies to. The second difference is that more and more quickly extends a predicate of events to a relation between events and degrees, whereas gradually requires such a relation to begin with.

Finally, the third way is for a degree argument to be introduced by a degree finction. The idea behind a degree function is that it maps events, objects, and relations between events and objects into degrees such that the degrees directly reflect how an object 'measures out' an event with respect to the relation in question. A degree function has the applicability condition defined in (27a) and satisfies the principle of extendability to proper parts given in (27b).

a.

Let $\delta$ be a function from (triples of) events e, objects $\mathrm{x}$, and relations $\mathrm{R}$ between events and objects to degrees $d . \delta$ is a degree function iff

a. $R(e, x) \wedge \forall x^{\prime}\left[R\left(e, x^{\prime}\right) \rightarrow x^{\prime}=x\right] \wedge \forall e^{\prime}\left[e^{\prime} \sqsubset_{\text {ini }} e \rightarrow \exists x^{\prime}\left[x^{\prime} \sqsubset x \wedge R\left(e^{\prime}, x^{\prime}\right)\right]\right] \leftrightarrow$ $\exists \mathrm{d}[\delta(e, x, R)=d]$

(Applicability condition for $\delta$ )

${ }^{8}$ The formula in (26d) asserts that as the event in which Mary runs unfolds, its degree of quickness steadily increases. The analysis of more and more quickly in (26c) is too strong as it stands (in particular, the increase in quickness should be more 'coarse-grained' than stated), but I set this complication aside here. In a more detailed account it would be important to guarantee that Mary gradually ran more and more quickly entails Mary ran more and more quickly but not vice versa. As things stand, the two sentences are mutually entailing. 


\section{Happening gradually}

b. $\quad \delta(e, x, R)=d \rightarrow$

$$
\begin{aligned}
& \forall \mathrm{e}^{\prime} \forall \mathrm{x}^{\prime}\left[\mathrm{e}^{\prime} \check{\text { ini }}_{\text {i }} \text { e } \wedge \mathrm{x}^{\prime} \sqsubset \mathrm{x} \wedge \mathrm{R}\left(\mathrm{e}^{\prime}, \mathrm{x}^{\prime}\right) \rightarrow \exists \mathrm{d}^{\prime}\left[\delta\left(\mathrm{e}^{\prime}, \mathrm{x}^{\prime}, \mathrm{R}\right)=\mathrm{d}^{\prime} \wedge \mathrm{d}^{\prime}<\mathrm{d}\right]\right] \\
& (\delta \text { extends to proper parts })
\end{aligned}
$$

The effect of the applicability condition in (27a) is that $\delta$ returns a value just in case object $x$ uniquely and incrementally reflects the development of event e with respect to relation $\mathrm{R}$. The principle in (27b) states that if $\delta$ applies to event e, object $x$, and relation $R$, then it returns a smaller value for any initial proper part of $e$ and proper part of $x$ that $R$ holds of.

Verbs that lack a degree argument can acquire one with the help of a degree function provided that they denote relations satisfying the condition in (27a). In general, this is what happens with accomplishments in order to combine with gradually (see (17) and (20)). Consider, for example, the derivation of (the relevant part of) (17c) with destroy: ${ }^{9}$

(28) a. destroy $\sim \lambda \mathrm{y} \lambda \times \lambda \mathrm{e}[\operatorname{Destroy}(\mathrm{e}, \mathrm{x}, \mathrm{y})]$

b. $\quad \delta \leadsto \lambda \operatorname{R} \lambda \mathrm{y} \lambda \mathrm{x} \lambda \mathrm{d} \lambda \mathrm{e}\left[\delta\left(\mathrm{e}, \mathrm{y}, \lambda \mathrm{y}^{\prime} \lambda \mathrm{e}^{\prime}\left[\mathrm{R}\left(\mathrm{e}^{\prime}, \mathrm{x}, \mathrm{y}^{\prime}\right)\right]\right)=\mathrm{d}\right]$

c. destroy $\delta \sim \lambda \mathrm{y} \lambda \mathrm{x} \lambda \mathrm{d} \lambda \mathrm{e}\left[\boldsymbol{\delta}\left(\mathrm{e}, \mathrm{y}, \lambda \mathrm{y}^{\prime} \lambda \mathrm{e}^{\prime}\left[\operatorname{Destroy}\left(\mathrm{e}^{\prime}, \mathrm{x}, \mathrm{y}^{\prime}\right)\right]\right)=\mathrm{d}\right]$

d. the disease destroy $\delta$ the motor neurons $\sim$ $\lambda \mathrm{d} \lambda \mathrm{e}[\boldsymbol{\delta}(\mathrm{e}$, The-motor-neurons,

$\lambda \mathrm{y}^{\prime} \lambda \mathrm{e}^{\prime}\left[\right.$ Destroy $\left(\mathrm{e}^{\prime}\right.$, The-disease, $\left.\left.\left.\left.\mathrm{y}^{\prime}\right)\right]\right)=\mathrm{d}\right]$

e. the disease gradually destroy $\delta$ the motor neurons $\leadsto$ $\lambda \mathrm{d} \lambda \mathrm{e}\left[\right.$ Gradual $\left(\mathrm{e}, \mathrm{d}, \lambda \mathrm{d}^{\prime} \lambda \mathrm{e}^{\prime}\left[\delta\left(\mathrm{e}^{\prime}\right.\right.\right.$, The-motor-neurons, $\lambda \mathrm{y}^{\prime} \lambda \mathrm{e}^{\prime \prime}\left[\right.$ Destroy $\left(\mathrm{e}^{\prime \prime}\right.$, The-disease, $\left.\left.\left.\left.\left.\left.\mathrm{y}^{\prime}\right)\right]\right)=\mathrm{d}^{\prime}\right]\right)\right]$

While it is clear that $\delta$ is applicable to any suitable relation between events and objects, it might also seem that $\delta$ overapplies. Take, for example, eat: $\delta$ should apply to eat in (29a) but not in either (29b) or (29c), and yet the internal argument relation of eat has the same properties in all three cases. In other words, if $\delta$ applies to eat, then what prevents eat from combining with a bare singular or plural object NP or with no object NP at all? Since many verbs pattern like eat in this respect (e.g. write and drink-see (14a) and (14b)), the analysis with $\delta$ is in danger of overgenerating.

(29) a. I gradually ate a big slice of cheesecake (at the party).

b. \#I gradually ate (at the party).

c. \#I gradually ate cheese (at the party).

\footnotetext{
${ }^{9}$ The simplest representation of ${ }^{\delta}$ is $\lambda R \lambda y \lambda d \lambda e[\delta(e, y, R)=d]$, which is applicable to intransitive verbs. The formula given in (28b) is a type-shifted variant of this, applicable to transitive verbs (e.g.
destroy in (28a)).
} 
A quick solution to this problem lies in differentiating related versions of eat at the lexical level by making the internal argument relation of eat available in (29a) but unavailable in (29b) and (29c). More precisely, whereas eat as a bona fide transitive verb is analyzed as in (30a), the intransitive version of eat is represented as in (30b), and the 'incorporating' version of eat is translated as in (30c). ${ }^{10}$
a. $\quad e_{\text {trans }} \sim \lambda y \lambda \times \lambda \mathrm{e}[\operatorname{Eat}(\mathrm{e}, \mathrm{x}, \mathrm{y})]$
b. $\quad$ eat $_{\text {intrans }} \leadsto \lambda \times \lambda \mathrm{e}[\exists \mathrm{y}[\operatorname{Eat}(\mathrm{e}, \mathrm{x}, \mathrm{y})]]$
c. $\quad$ eat $_{\text {incorp }} \sim \lambda \mathrm{P} \lambda \times \lambda \mathrm{e}[\exists \mathrm{y}[\operatorname{Eat}(\mathrm{e}, \mathrm{x}, \mathrm{y}) \wedge \mathrm{P}(\mathrm{y})]]$

Of these analyses of eat, it is clear that $\delta$ is applicable only to the first, because the internal argument is existentially quantified in the latter two. But if $\delta$ is not applicable to the intransitive and 'incorporating' versions of eat, then there is no way to derive the sentences in (29b) and (29c). Other contrasts of this sort would be treated similarly. ${ }^{11}$

\section{References}

van Geenhoven, Veerle. 1998. Semantic incorporation and indefinite descriptions: Semantic and syntactic aspects of West Greenlandic noun incorporation. CSLI Publications.

Hay, Jennifer, Christopher Kennedy, and Beth Levin. 1999. Scalar structure underlies telicity in 'degree achievements'. In Tanya Matthews and Devon Strolovitch (eds.), Proceedings of SALT 9, 127-144. Cornell Linguistics Circle Publications. Jackendoff, Ray S. 1972. Semantic interpretation in generative grammar. The MIT Press.

Krifka, Manfred. 1990. Four thousand ships passed through the lock: Objectinduced measure functions on events. Linguistics and Philosophy 13: 487-520.

Vendler, Zeno. 1967. Verbs and times. In Linguistics in philosophy, 97-121. Cornell University Press.

Seminar für Allgemeine Sprachwissenschaft

Universität Düsseldorf

Universitätsstr. 1

40225 Düsseldorf (Germany)

pinon@phil-fak. uni-duesseldorf.de

\footnotetext{
${ }^{10}$ The incorporation analysis presupposes a treatment of bare singular and plural NPs as one-place predicates and has been argued for independently by van Geenhoven (1998).

${ }^{11}$ Manfred Krifka suggested to me that the incorporation analysis might be relevant in ruling out examples such as (29c).
} 